\title{
Assessing Elementary School Teachers' Performance Using CBPAST and IPCR: A Five Year Trajectory Report
}

\author{
Cecilia Junio-Sabio and Monaliza M. Manalo
}

\begin{abstract}
This descriptive research is about the performance of Elementary School Teachers in Diliman Elementary School in San Rafael Bulacan. Using a secondary data on the actual results of Competency-Based Performance Appraisal System (CBPAST) and the Individual Performance Commitment Review (IPCR) performance assessment tool which are both government prescribed forms/tools for public school teachers in the Philippines, the researcher will show a five-year trajectory report (from 2013-2018) on the actual performance of elementary school teachers. Findings revealed that the public school elementary teachers generally yielded a "Very Satisfactory" rating in CBPAST and IPCR during the five year period. Since the two instruments (i.e. CBPAST and IPCR) are both self-assessment tools, it is recommended that a more subjective performance assessment tool be utilized like those that involves participation of the students and the immediate superior of the concerned public school teachers.
\end{abstract}

Index Terms-Elementary teachers, performance, public school.

\section{INTRODUCTION}

Great attention and consideration have always been given to the professional development of teachers throughout the history of education. Teachers play a vital role in the realization of the goals and objectives of a country's educational system. "The teacher is the indispensable element in the school" (Beerens, 2000) [1].

Alvior (2014) [2] posits that pressures are created among educators to prepare students such that they will possess a wide range of skills, content knowledge, and practical experiences needed to survive in this highly competitive world. This, according to Alvior, is based on the result of today's knowledge-based economy and the rapid explosion of networked communications across the globe.

In the Philippines, according to Lapus (2008) [3] the Department of Education has recognized the importance of acquiring the 21 st century skills through the integration of Information and Communication Technology (ICT) in the educational process. Despite economic difficulties and budget deficit, the government through the Department of Education (DepEd) continues to invest in teacher professional development across the country. The obvious reason is to improve educational standards to compete in globalized knowledge economy. The recent passing of the

Manuscript received June 30, 2019; revised December 15, 2019.

Cecilia Junio-Sabio is with Graduate School, De La Salle Araneta University and University of the City of Manila, Philippines (e-mail: vpcfjs@gmail.com).

Monaliza M. Manalo is with Diliman Elementary School, Philippines (e-mail: monalizammanalo27@gmail.com).
Republic Act 10912, [4] otherwise known as the "Continuing Professional Development (CPD) Act of 2016, which mandates professionals (including teachers) to obtain the necessary CPD units as prescribed by their respective Professional Regulatory Board (PRB) to renew their Professional Identification Card (PIC), shows the emphasis being given to professional development.

However, the study of Maligalig and Albert (2008) [5] showed that the contributing factor for low quality basic education in the country is the lack of competent teachers. This result is in consonance to the reforms stipulated in the Basic Education Sector Reform Agenda (BESRA) particularly in the Key Reform Thrust 2 that there is a need to improve the classroom performance of English, Mathematics, and Science teachers for better learning outcomes (Alvior, 2014). While considerable amounts of money have been spent by the government, private educational institutions, and individual teachers on professional development, researches have little evidence of its impact on teachers' professional practice. Similarly, there is little evidence that exists regarding its effect on pupils' outcomes (O'Sullivan, 2011; King, 2011) [6].

For the Filipino teachers, Individual Performance Commitment Review Form (IPCRF) was introduced to DepEd 2015. It is a general plan of task and serves as guide to teachers to be written before the start of classes, implemented before the school year and to be rated at the end of the school year. This is a tool to evaluate performance. As stated in DepEd Order 2, S. 2015 [7] - Guidelines on the Establishment and Implementation of the Results-Based Performance Management System (RPMS) in the Department of Education (DepEd), it aims to provide comprehensive guidelines for the adoption of the Civil Service Commission's (CSC) Strategic Performance Management System (SPMS) in DepEd. According to Canoma (2017) [8], the objectives indicated are actually the duties and responsibilities that each teacher must do in service. This is a tool to check and balance if one is doing his duties diligently with quality, efficiency and on time.

Prior to this, Competency-Based Performance Appraisal System for Teachers (CB_PAST) was used as the performance evaluation tool in connection with professional development. CB-PAST is a comprehensive appraisal system which addresses one of the mandates of the Department as embodied in the RA 9155 [9] (An Act Instituting A Framework of Governance for Basic Education, Establishing Authority and Accountability, Renaming The Department of Education, Culture And Sports as the Department Of Education, and For Other Purposes). The first purpose is formative-developmental in nature which will 
provide teachers with meaningful activities that encourage their professional learning and growth. The procedure will be supportive, non-threatening, fair, collegial and self-directed within the community of professional learners. The second purpose is summative-evaluative which will assure that school learners have the benefit of instruction at high level of proficiency from the teachers. Appraisal of teacher performance is made on the basis of the evidences collected, observations made, conferences, and dialogues that accompany each procedure. The ultimate intention of the performance appraisal is achieving high levels of learners' performance and improved learning outcomes as part of the school outcomes.

\section{OBJeCTIVE}

This research attempted to determine the performance of elementary school teachers using CBPAST and IPCR performance assessment tool. A five year trajectory report (from 2013-2018) will be presented to document how the teacher's fare in their performance using the 2 instruments. The goal is to somewhat help improve teacher performance through proposed professional development activities (should the result will prove to be low) which is ultimately aimed at enhancing pupil/student learning outcomes and foster school improvement. Specifically, this research sought answer to the following:

1) What is the profile of the respondents in terms of:
a) age;
b) ex;
c) designation;
d) highest level of formal education completed;
e) length of service in teaching;
f) length of service in Diliman Elementary School?

2) How do the teachers fare in their performance for the past five years using CBPAST and IPCR?

\section{THE SUBJECT}

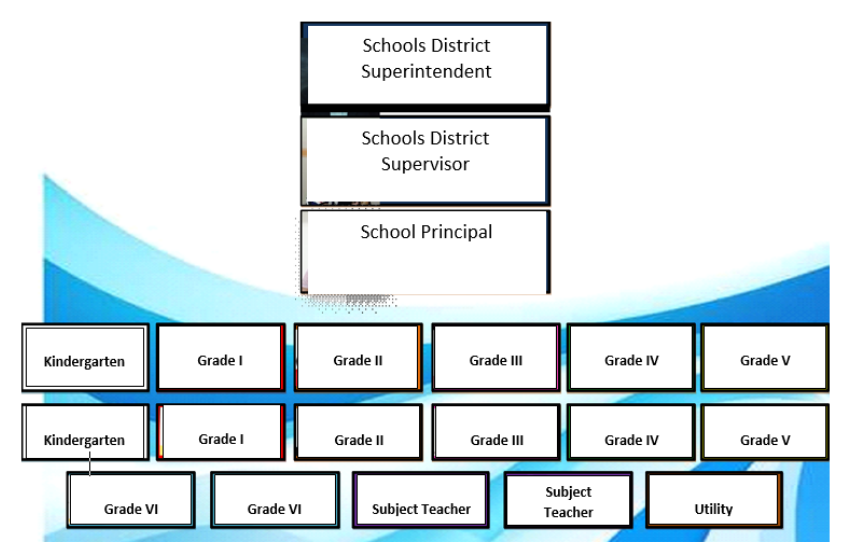

Fig. 1. Diliman elementary school (DES) organizational chart.

This research is set in the context of schools continuing effort to invest in teacher professional development (PD) to enhance educational standards and teachers' performance. The Dilliman Elementary School (which is the subjects of this research) is a government school located in San Rafael, Bulacan and is operating under the supervision of the
Department of Education. Currently, the school operates with a total of 17 teachers (including the Principal) with an average number of 32 students per section from grade 1 to grade 6 . Each grade level (grade 1 to 6) has 2 sections. Only the kinder level has 3 sections with an average of 27 students per section.

Fig. 1 shows the organizational structure of Diliman Elementary School.

\section{METHOD}

Descriptive quantitative method was used in this study. Descriptive quantitative as it gathers quantifiable information that can be used for statistical inference on the target audience through data analysis; a method to reveal and measure the strength of a target group's opinion, attitude, or behavior with regards to a given subject. It described characteristics of the population being studied and was used for frequencies and averages of the characteristics which occurred. The description is used and other statistical calculations. Secondary data on the CBPAST and IPCR were used to get the trajectory report for the past five years (2013-2018).

The teachers of Diliman Elementary School for the academic year 2018-2019 comprising of 15 members, excluding the principal and one of the researcher, were the respondents of the study. The goal of this research is to provide quantitative description and an in-depth detail, rich description, and clear documentation of DES teachers' profile and performance.

The first part of the data gathering instrument that was used in this research basically drew the baseline information about the Elementary School teacher's profile. Part II dealt with the participants' actual performance evaluation result which were drawn from the Individual Performance Commitment Review (IPCR) and the Competency-Based Performance Appraisal System for Teachers (CB_PAST).

IPCR is an assessment tool for government employees' use that will rate task accomplished for a year. It is composed of Key Result Areas (KRAs) which dwells on Instructional competence, Learning Outcomes, Professional Growth, Community Involvement and the Special Task which should have at least 15 objectives with corresponding timeline and weight. In order to determine the score obtained, there are performance indicators which shows how the objective were performed with ratings: 5-Outstanding, 4-Very Satisfactory, 3-Satisfactory, 2-Unsatisfactory and 1-Poor Performance.

The rating scale is based on the Civil Service Commission Memorandum Circular No. 06, series of 2012 [10] that sets the guidelines on the establishment and implementation of the Strategic Performance Management System (SPMS) in all government agencies is interpreted in Table I below:

CB_PAST on the other hand is divided into two parts. Part I constitutes the Components and Performance Standards which include (I) Instructional Competence taking into considerations the (A) Diversity of Learners, (B) Curriculum Content and Pedagogy, (C) Planning, Assessing and Reporting; (II) Home, School and Community Involvement which accounts for (D) Learning Environment and (E) Community Linkages; and (III)Personal Growth and 
Professional Development evaluating the (F) Social Regard for Learning, and (G) Personal, Social Growth and Professional Development. Part II constitutes the Plus Factor for the same components and performance standards mentioned in Part I. There are different statements under each given indicators and the teacher will rate accordingly from an index of 1 to 4 described as (1) Below Basic, (2) Basic, (3) Proficient, and (4) Highly Proficient interpreted as shown in Table II.

\begin{tabular}{lll}
\multicolumn{2}{c}{ TABLE I: INDIVIDUAL PERFORMANCE COMMITMENT REVIEW (IPCR) } \\
RATING SCALE AND INTERPRETATION
\end{tabular}

\begin{tabular}{lll}
4 & $\begin{array}{l}\text { VERY } \\
\text { SATISFACTORY }\end{array}$ & $\begin{array}{l}\text { Performance exceeded expectations. All goals, } \\
\text { objectives and target were achieved above the } \\
\text { established standards. }\end{array}$ \\
2 & SATISFACTORY & $\begin{array}{l}\text { Performance met expectations in terms of } \\
\text { quality of work, efficiency and timeliness. The } \\
\text { most critical annual goals were met. }\end{array}$ \\
1 & POOR & $\begin{array}{l}\text { Performance failed to meet expectations, } \\
\text { and/or one or more of the most goals were not } \\
\text { met. }\end{array}$ \\
& $\begin{array}{l}\text { Performance was consistently below } \\
\text { expectations, and/or reasonable progress } \\
\text { toward critical goals was not made. Significant } \\
\text { improvement is needed in one or more } \\
\text { important areas. }\end{array}$ \\
\hline
\end{tabular}

TABLE II: TEACHER PERFORMANCE INDEX

3.51-4.00 Highly Proficient. Teacher performance consistently exceeds expectations. Displays at all time, a consistently high level of performance related skills, abilities, attributes, initiatives and productivity. All assignments/responsibilities are completed beyond the level of expectation. Self-direction of the teacher is evident.

2.51-3.50 Proficient. Teacher performance often exceeds expectations. Displays a high level of competency related skills, abilities, initiatives and productivity, exceeding requirements in many of the areas.

1.51-2.50 Basic. Teacher performance meets basic expectations based on standards. Displays basic level of work and performance outputs as required outcomes or expectations of the job.

1.00-1.50 Below Basic. Teacher performance on the job and outputs frequently fall below standards. Work outputs consistently low, regularly fails to meet required outcomes needing repetition of duty or by completion of others. The teacher may need immediate instructional support.

Note: Overall performance is computed by adding the Formative Performance Rating (Sum of the Total Weighted Average of I, II and III) and Plus Factor (for the Summative Appraisal) which totaled to Summative Performance Rating.

Table III shows the Rating Scale and Interpretation for Competency-Based Performance Appraisal System for Teachers )CB_PAST)
TABLE III: COMPETENCY-BASED PERFORMANCE APPRAISAL SYSTEM FOR TEACHERS (CB_PAST) RATING SCALE AND INTERPRETATION

\begin{tabular}{cl}
\hline $\begin{array}{c}\text { Description of Overall } \\
\text { Performance }\end{array}$ & $\begin{array}{c}\text { Critical Requirements } \\
\text { Notequirement will get the lower } \\
\text { performance rating. }\end{array}$ \\
\hline Outstanding & $\begin{array}{l}3.51 \text { or higher and no performance index of } \\
\text { below proficient in any of the standards. } \\
2.51-3.50 \text { and no performance index value of } \\
\text { below basic in any of the standards. } \\
1.51-2.50 \text { and no performance index value of } \\
\text { below basic in any of the standards. } \\
1.00-1.50 \text { with at least one performance index } \\
\text { value of below basic in any of the standards. }\end{array}$ \\
Satisfactory &
\end{tabular}

\section{RESUlTS AND DisCUSSION}

1) The profile of the teacher-respondents are as follows:

a) In terms of Age. Highest percentage $(88 \%)$ of the respondents belonged to the middle age (26 - 45 years old), while lower percentage $(6.67 \%)$ of them belonged to the older adulthood ( $56-60$ years old).

The findings show that professional development for teachers should be analogous to professional development for other professionals regardless of age. It is a continuous process that stretches from pre-service experiences in undergraduate years to the end of a professional career. This is supported by what Organization for Economic Cooperation and Development (OECD) in 2005 states that effective professional development is on-going.

b) In terms of Gender/Sex. 13 percent of the respondents were males while 87 percent of them were females.

The findings reveal that implementing high quality professional learning is critical to teacher effectiveness in meeting students' needs but there is no one fits all approach, differences in communities of teachers uniquely affect professional development.

c) 1.3. In terms of Designation. Teacher 1 ranked 1 with the highest percentage $(60 \%)$, while lowest percentage $(6.67 \%)$ was Master Teacher 1.

The data can be analyzed in the light of the speech delivered by Representatives Tinio and Castro of ACT Teachers Party-list, that teachers' career advancement is hindered by the sluggish processing of promotion in DepEd, the imposition of numerous requirements, and certain limitations such as the scarcity of plantilla items for higher positions and the setting of ratios between teaching items.

d) 1.4. In terms of Highest level of formal education completed. Highest percentage $(86.67 \%)$ of the respondents were holders of college degree while the lowest percentage (13.33\%) were holders of Master's degree.

Thus, Sec. Briones of the Department of Education called the teachers to take new and exciting paths, know and love the country more, discover things never known before, and learn skills they never had before.

e) 1.5. Length of service in teaching. 46.67 percent of the respondents taught for not less than 5 years, while 6.67 percent had been teaching for not less than 30 years. The remaining percent 46.67 percent belonged from 6 -25 number of years in service. 
What makes the novice and expert teachers different is their background teaching experiences. There is an Arabic proverb which goes like experience is superior to knowledge.

f) 1.6. Length of service in Diliman Elementary School (DES). Highest percentage $(73.33 \%)$ have been teaching in DES for not less than 5 years. $13.33 \%$ taught in DES between $6-10$ years, $6.67 \%$ between $11-15$ years and $6.67 \%$ between $16-20$ years.

2) Elementary School Teachers Performance using CB_PAST and IPCR

TABLE IV: OVER-All RATING THRU COMPETENCY-BASED PERFORMANCE APPRAISAL SYSTEM FOR TEACHERS (CB_PAST) AND PERFORMANCE EVALUATION RESULTS (IPCR) FOR 5-YEAR PERIOD

\begin{tabular}{|c|c|c|c|c|c|c|c|c|c|c|c|}
\hline \multirow{3}{*}{$r^{e^{x^{2}}}$} & \multirow{2}{*}{\multicolumn{2}{|c|}{$\begin{array}{l}2013- \\
2014\end{array}$}} & \multirow{2}{*}{\multicolumn{2}{|c|}{$\begin{array}{c}2014- \\
2015\end{array}$}} & \multirow{2}{*}{\multicolumn{2}{|c|}{$\begin{array}{c}2015- \\
2016\end{array}$}} & \multirow{2}{*}{\multicolumn{2}{|c|}{\begin{tabular}{|c|}
$2016-$ \\
2017 \\
\end{tabular}}} & \multirow{2}{*}{\multicolumn{2}{|c|}{$\begin{array}{c}2017= \\
2018\end{array}$}} & \multirow{3}{*}{ Mean } \\
\hline & & & & & & & & & & & \\
\hline & \multicolumn{2}{|c|}{ Rating } & \multicolumn{2}{|c|}{ Rating } & \multicolumn{2}{|c|}{ Rating } & \multicolumn{2}{|c|}{ Rating } & \multicolumn{2}{|c|}{ Rating } & \\
\hline A & VS & 3.07 & VS & 3.07 & VS & 4.28 & VS & 4.45 & $\mathrm{O}$ & 4.5 & 3.87 \\
\hline B & VS & 3.07 & VS & 2.98 & VS & 4.47 & VS & 4.47 & $\mathrm{O}$ & 4.52 & 3.9 \\
\hline $\mathrm{C}$ & VS & 2.73 & VS & 2.98 & VS & 4.49 & VS & 4.46 & VS & 4.49 & 3.83 \\
\hline $\mathrm{D}$ & VS & 2.98 & VS & 2.98 & VS & 4.32 & VS & 4.4 & VS & 4.48 & 3.83 \\
\hline $\mathrm{E}$ & VS & 2.98 & VS & 2.65 & $\mathrm{O}$ & 4.5 & VS & 4.48 & $\mathrm{O}$ & 4.51 & 3.82 \\
\hline $\mathrm{F}$ & VS & 2.65 & VS & 2.74 & VS & 4.46 & VS & 4.44 & VS & 4.49 & 3.76 \\
\hline G & & & VS & 2.7 & VS & 4.3 & VS & 4.38 & VS & 4.48 & 3.97 \\
\hline $\mathrm{H}$ & & & VS & 2.65 & VS & 4.43 & VS & 4.48 & VS & 4.49 & 4.01 \\
\hline I & & & VS & 2.74 & VS & 4.4 & VS & 4.45 & VS & 4.48 & 4.02 \\
\hline $\mathrm{J}$ & & & VS & 2.98 & VS & 4.36 & VS & 4.41 & VS & 4.49 & 4.06 \\
\hline $\mathrm{K}$ & & & & & VS & 4.41 & VS & 4.44 & 0 & 4.57 & 4.47 \\
\hline $\mathrm{L}$ & & & & & & & VS & 4.44 & VS & 4.48 & 4.46 \\
\hline M & & & & & & & & & VS & 4.4 & 4.4 \\
\hline $\mathrm{N}$ & & & & & & & & & VS & 4.48 & 4.48 \\
\hline Mean & & 2.91 & & 2.85 & & 4.4 & & 4.44 & & 4.49 & 3.82 \\
\hline Interpret & ation & VS & & $\mathrm{VS}$ & & VS & & VS & & VS & VS \\
\hline
\end{tabular}

LEGEND: (for IPCR covering SY 2015-2016, 2016-2017 and 2017-2018)

$4.500-5.000 \quad$ Outstanding $(O)$

$3.500-4.499 \quad$ Very Satisfactory (VS)

$2.500-3.499 \quad$ Satisfactory $(S)$

$1.500-2.499 \quad$ Unsatisfactory (US)

Below $1.4999 \quad$ Poor $(P)$

Table IV shows the change in teacher's classroom practices as determined by the Over-All Rating Thru Competency-Based Performance Appraisal System for Teachers (CB-PAST) and Performance Evaluation Result (IPCR) for 5-year Period. There were no entries for nine teachers. This means that those teachers were not present during those years. It can also be observed that in 2014-2015, four teachers have no entries. The reason for this is they had not been hired yet in DES during that time. For the SY 2015-2016, three teachers have no entries meaning they were not yet teaching at DES. Lastly, for 2016-2017, two teachers have no entries which implies that they were not hired yet.

Table IV also reveals that looking at the individual rating of those teachers with a 5-year minimum number of years in DES, there was not really tremendous change but mostly were rated Very Satisfactory from year 1 to Year 5 like teachers C, D and F. Teachers A and B consistently rated as Very Satisfactory for the first four consecutive years and became Outstanding for the last year. However, it can be noted that Teacher E was rated Very Satisfactory during the first two years, became Outstanding on the third year, goes back to Very Satisfactory on the fourth year and finally became Outstanding.

As per school year, it can be seen that the mean rating of teachers remained at the Very Satisfactory level. It started from 2.91 in the School Year 2013-2014, then it went down to 2.85 on the second year, 2014-2015. On the third year, 2015-2016, it increased to 4.40. This difference in the numerical rating is brought about by the change of performance evaluation tool from CB_PAST to IPCR as discussed in the data gathering instrument. This increased further on the fourth and fifth school years to 4.44 and 4.49 respectively.

It further represents the performance per teacher for school years 2013-2018 which implies an increase in the rating of teachers' classroom practices. Teachers K, L, M, and N shows a higher rating as compared to Teachers A-J. The number of years in DES is a factor for such difference in performance. The longer the number of years teaching at DES, the lower the numerical rating tends to be due to the shift of evaluation tools used in the earlier years. This can be explained by the change in the use of assessment tool starting School Year 2015-2016. Those who were evaluated using the IPCR reflected higher means compared to those with CB_PAST ratings in the previous years.

The findings serve the very purpose of accomplishing the IPCR being the general plan of task which serves as guide to teachers and a tool to evaluate performance (DepEd Order 2, S. 2015)

\section{CONCLUSION}

Most of the teacher-respondents belong to the age group ranging from 26-45, majority are female, and mostly occupy Teacher 1 position. Majority are bachelor degree holders while almost half of the respondents had been in the service for not greater than 5 years. Most of the teachers had been teaching at DES for not greater than 5 years. There was no remarkable change in teachers' performance were noted as they were all rated "Very Satisfactory;" this is regardless whether CBPAST or IPCR was used. Since the two instruments (i.e. CBPAST and IPCR) are both self-assessment tools, it is recommended that a more subjective performance assessment tool be utilized like those that involves participation of the students and the immediate superior in the performance evaluation system. In line with the conclusions made, the following recommendations are hereby offered: Give seminars to teachers based on training needs analysis to optimize their potential which may lead them to higher performance evaluation result. Adopt a training plan for DES since this is based on the current needs of the teachers, a training plan can also help the students enhance their learning outcomes in English, Mathematics, and Science which will also be beneficial on the part of the school.

\section{CONFLICT OF INTEREST}

The authors declare no conflict of interest.

AUTHOR CONTRIBUTIONS 
Dr. Cecilia J. Sabio checks the research methodology and serves as grammarian of the paper. Mrs. Monaliza M. Manalo conducted the research and wrote the initial draft.

The authors work collaboratively in coming up with the final draft of the paper. All authors approved the final version.

\section{REFERENCES}

[1] D. R. Beerens, Evaluating Teachers for Professional Growth: Creating a Culture of Motivation and Learning, Thousand Oaks, CA: Sage Publications, 2000

[2] C. Alvior, The Basics of Social Research, Belmont, California: Wadsworth Cengage, pp. 303-04, 2014.

[3] J. A. Lapus, "The education system facing the challenges of the $21 \mathrm{st}$ century country: Republic of the Philippines," 2008

[4] RA 10912, "An act mandating and strengthening the continuing professional development program for all regulated professions," Creating Continuing Professional Development Council and Appropriating Funds Therefore and for Other Related Purposes, Manila, Philippines, 2015.

[5] A. M. Maligalig, "Sinag teachers' summit," Sun Life Financial Philippines, Novotel Manila, Araneta Center, Quezon City, Philippines, 2018.

[6] H. O'Sullivan, "Leading and managing professional learning in schools," Leading and Managing Schools, London: Sage Publications Ltd., pp. 111-125, 2011.

[7] DepEd Order No.2 S.2015, Guidelines on the Establishment and Implementation of the Results-Based Performance Management System (RPMS) in the Department of Education.

[8] RA 9155 (2001), Governance of Basic Education Act of 2001, An Act Instituting a Framework of Governance for Basic Education, Establishing Authority and Accountability, Renaming the Department of Education, Culture and Sports as the Department of Education, and for other Purposes. Manila, Philippines.

[9] M. Canoma, "The benefit to professional development," American Educator. vol. 26, no. 2, 2225, 2017.
[10] MC No. 6, 2012 - Guidelines in the Establishment and Implementation of Agency SPMS.

Copyright $\odot 2020$ by the authors. This is an open access article distributed under the Creative Commons Attribution License which permits unrestricted use, distribution, and reproduction in any medium, provided the original work is properly cited (CC BY 4.0).

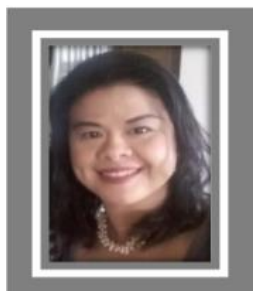

Cecilia Junio-Sabio Sabio was was the former vice president for Academic Affairs and held the rank of SUC Vice President IV at the Pamantasan ng Lungsod ng Maynila (University of rhe City of Manila). She holds professor V academic rank in the same University. She has previously worked at the Commission on Higher Education (CHED), Office of the Chairman, Office of the President of the Philippines and a GOCC holding various management and executive position. She was the former Head of the Research and Industry Engagement Center of the Gulf College based in Muscat Oman which is in collaboration with Staffordshire University, University of Reading and Hull University London, UK. She also teaches in DLSAU and PUP Graduate Schools.

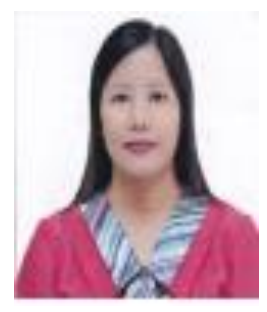

Monaliza M. Manalo is from Diliman, San Rafael, Bulacan, Philippines. She was born on April 27, 1978. Currently she is pursuing the master of arts in educational major in educational administration at De La Salle Araneta University in Malabon city, Metro Manila.

She is a master teacher I at Diliman Elementary School (DES) at Diliman, San Rafael, Bulacan, Philippines. She is interested in making researches about educational management.

Mrs. Manalo is an active member of Bulacan Public School Teachers Association. 